\title{
Türkiye'de İmalat Sanayi ve Tarım Sektörlerinin Ekonomik Büyüme Üzerine Etkisi: 1998-2020 Dönemi Analizi
}

\author{
Ezgi KOPUK* $\quad$ Oytun MEÇİK **
}

\begin{abstract}
$\ddot{O} Z$
Bu çalışma Türkiye ekonomisinin önemli sektörleri olan imalat sanayi ile tarım sektörlerinin diş ticaretinin ekonomik büyüme üzerindeki etkilerini tespit etmeyi amaçlar. 1998 birinci çeyrek ve 2020 birinci çeyrek dönemini kapsayan analizde, sektörlerin diş ticaret değerleri ve GSYH verileri kullanılarak zaman serisi teknikleri ışı̆̆ında; birim kök testleri ve Johansen eşbütünleşme testi uygulanmıştır. Ayrıca Granger nedensellik testi ile değişkenler arasındaki ilişkinin; tarım sektöründen GSYH'ye tek yönlü ve tarımdan imalat sanayiine doğru çift yönlü bir Granger nedenselliğin söz konusu olduğu gözlemlenmiştir. Böylece tarım-imalat sanayi sektörleri arasında geri bildirim hipotezinin geçerli olduğu sonucuna varılmıştır. Dolayısıyla imalat sanayi ile tarım sektörlerine yapılan yatırımların, büyümenin bir nedeni olduğu ve aralarındaki ilişki göz önünde bulundurularak, politika yapıcıların bu sektörleri öne alan politikalar gelişstirmesinin makroekonomik açıdan ülke ekonomisine yararlı olacă̆ ifade edilebilir.
\end{abstract}

Anahtar Kelimeler: Ekonomik Büyüme, Tarım, Imalat Sanayi

JEL Sinıflandirması: F1, F43, L6, O13

\section{The Effect of Manufacturing Industry and Agricultural Sector on Economic Growth in Turkey: Analysis of 1998-2020 Period}

\begin{abstract}
This study aims to determine the effects of foreign trade of manufacturing industry and agriculture sectors which the key sectors of the Turkish economy on economic growth. Foreign trade values and GDP data of the sectors were analyzed for 1998Q1 and 2020Q1 by applying unit root test and Johansen Cointegration test, which are time series methods. In addition, in the analysis, it was observed that there is a one-way Granger causality from agriculture to GDP and two-way agriculture to the manufacturing industry. Thus, it was concluded that the feedback hypothesis between the agriculture and manufacturing industries is valid. Therefore, considering the investments made in the manufacturing industry and agriculture sectors as a reason for growth and relationship between them, it can be stated that it will be beneficial for the economy of the country in terms of the development of policymakers to develop policies that emphasize these sectors.
\end{abstract}

Key Words: Economic Growth, Agricultural, Manufacturing Industry

JEL Classification: F1, F43, L6, O13

\section{GíRiş}

Ülkeler makroekonomik açıdan ekonomik büyüme ile refah seviyelerini uzun vadede artırma hedefi sergilerler. Ekonomik büyümenin ülkeler için sahip

\footnotetext{
* Doktora Öğrencisi, Eskişehir Osmangazi Üniversitesi, Sosyal Bilimler Enstitüsü, İktisat Anabilim Dalı, ezgi.kopuk@ @otmail.com, ORCID Bilgisi: 0000-0001-7242-1160

*** Doç. Dr., Eskişehir Osmangazi Üniversitesi, İktisadi ve İdari Bilimler Fakültesi, İktisat Bölümü, oytunm@ ogu.edu.tr, ORCID Bilgisi: 0000-0002-7409-6266
} 
olduğu önem, ülkelerin ekonomik büyüme politikalarına etki eden faktörleri belirlemelerini ve bu doğrultuda politikalar geliştirmelerini gerektirir.

Günümüzde ülkelerin ekonomik büyümenin önemli dinamiklerinden biri dış ticaret faaliyetleri olarak gösterilebilir. Küreselleşen dünya ekonomisi, ekonomik sınırlılıkların kaldırılıp ticaretin uluslararası bir boyuta ulaşması yoluyla büyüme üzerinde pozitif etkilere yol açmaktadır. Bu pozitif etkinin oluşabilmesi için ise ülkelerin dış ticaret gelirlerinin artması ve bunun için de sürdürülebilir bir ihracat artışının sağlanması gerekmektedir. Ülkeler bu sayede dünya ekonomisinin bir parçasını oluşturmaktadırlar.

İmalat sanayi ve tarım sektörleri bir ülkenin gelişiminin bel kemiği konumundadır. Özellikle birincil sektörü oluşturan tarım ve hayvancılık alanındaki iktisadi faaliyetler, ülkelerin makroekonomik gelişiminde önemli bir rol oynamaktadır. Bu aynı zamanda ülkeler için temel gıda, gelir ve istihdam kaynağı teşkil etmektedir.

Tarihsel perspektifte de gözlendiği gibi, az gelişmiş ve gelişmekte olan ülkeler öncelikle temel gıda ve barınma ihtiyaçlarını karşılayabildikten sonra, sanayi üretimini geliştirmeye başlarlar. Bütün çağlar boyunca insanlar varlıklarını sürdürebilmek için önce tarım sektörünü, bu sektördeki verimlilik artışı sonucunda da elde ettikleri kaynakların sanayi sektörüne akmasını sağlayarak, büyüme için bu sektörlerin katkı sağladığı önemli bir dinamik oluşmasını sağlamışlardır.

Kalkınma ekonomisi çerçevesinde İkinci Dünya Savaşı'nın dünya ülkelerinin bugünkü iktisadi koşullara ulaşmasında yadsınamaz bir role sahip olduğu değerlendirilmektedir. Zira savaş sonrası dönem sanayinin büyük bir gelişme sağlamasıyla birlikte sanayi sektörünün ekonomik büyüme üzerine olan etkileri araştırılmaya başlanmıştır. R. Nurkse, A. Lewis, R. Prebisch, H. Chenery, C. Clark, S. Kuznets, N. Kaldor gibi ünlü iktisatçılar sanayi ile ekonomik büyüme arasındaki ilişkiyi araştırmışlar ve ülkelerin gelişimini temelde, sanayi sektöründeki gelişmeye bağlamışlardır (Mercan ve Kızılkaya, 2014: 138).

Kaldor'a göre GSYH ile üretim arasında büyük bir ilişki vardır. $\mathrm{Bu}$ görüşten yola çıarak, ülke gelişiminin temel faktörünün üretime dayandığ söylenebilir. Üretim artışı, mal üretimi olarak ele alındığında, tarım sektörü ve imalat sanayinin önemi ortaya çıkacaktır. Aynı zamanda, bu üretilen malların niteliklerinin ve verimliliklerin geliştirilmesi üretici firmanın gelişimine katkı sağlayacağı gibi ülke ekonomisine de olumlu etki sağlayacaktır (Öztürk ve Altınöz, 2018: 19).

İmalat sanayi ve tarım sektöründe üretimin artmasıyla sürdürülebilir kalkınmanın çevresel, sosyal, ekonomik ve kurumsal tüm unsurları pozitif yönde etkilenerek büyümeyi artırır (Behun, Gavurova, Tkacova ve Kotaskova, 2018: 23). $\mathrm{Bu}$ unsurlara etki edecek verimlilik, ham madde tedariki, teknoloji, yenilikler, işgücünün niteliğinin geliştirilmesi gibi faktörlerinde geliştirilmesiyle imalat sanayi ve tarım sektörünün GSYH'ye katkısı daha fazla olacaktır.

Bu bilgiler ve incelenen literatür kapsamında çalışmanın temel amacı, 1998 birinci çeyrek ve 2020 birinci çeyrek döneminde Türkiye'nin imalat sanayi ve tarım sektörlerinin net dış ticaretinin ekonomik büyüme üzerine etkisini belirlemektir. Bu 
etkinin belirlenmesi için, zaman serisi tekniklerine dayalı olarak; öncelikle serilerin durağanlıkları ADF ve PP Birim Kök Testleri ile belirlenmiş ve ardından bu değişkenler arasında ilişki uygun eşbütünleşme test ile sınanmıştır. Son olarak ise Granger Nedensellik Testi ile değişkenler arasındaki ilişkinin yönü belirlenmiştir. Analiz bulgularına dayalı olarak Türkiye'de makroekonominin büyüme süreci açısından imalat sanayi ve tarım sektörlerinin dış ticaretteki rolleri üzerinden tasarlanan politika önerileri geliştirilmiştir.

\section{LITERATÜR}

Makroekonominin üretim ve üretilen değerlerin ticari faaliyetlere konu olmasına yönelik reel boyutu büyük bir yelpazeye sahiptir. Reel ekonomi, sektörler düzeyinde ele alındığında bile makroekonomi açısından büyük paydayı oluşturduğu bir gerçektir. Bu çalışmada ise ekonominin en temel iki sektörü olan imalat sanayi ve tarım sektörlerinin dış ticaret faaliyetlerinin ekonomik büyüme üzerindeki etkileri konu edinilmektedir.

Ekonominin birincil ve ikincil sektörleri olan bu sektörlerin ekonomik büyüme ile ilişkisini çeşitli ampirik yöntemlerden yararlanarak ele alan bir literatür söz konusudur. $\mathrm{Bu}$ literatüre dair genel özellikler Tablo 1 yardımıyla tasnif edilmiştir.

Tablo 1. Literatür Özeti

\begin{tabular}{|c|c|c|c|}
\hline Yazar-Yıl & Dönem-Yer & Yöntem & Bulgular \\
\hline $\begin{array}{l}\text { Mercan ve } \\
\text { Kizilkaya } \\
(2014)\end{array}$ & $\begin{array}{l}\text { 1988Q1- } \\
\text { 2013Q3 } \\
\text { Türkiye }\end{array}$ & $\begin{array}{c}\text { Johansen } \\
\text { eşbütünleşme ve } \\
\text { Granger } \\
\text { nedensellik testi }\end{array}$ & $\begin{array}{l}\text { Test sonuçlarına göre imalat sanayi ve ekonomik } \\
\text { büyüme arasında paralel bir ilişkinin varlığ tespit } \\
\text { edilmiştir. }\end{array}$ \\
\hline $\begin{array}{c}\text { Novel ve } \\
\text { Marsal (1998) }\end{array}$ & $\begin{array}{l}\text { 1984-1992 } \\
\text { Avrupa } \\
\text { Ülkeleri }\end{array}$ & OLS yöntemi & $\begin{array}{l}\text { Mekânsal otokorelasyonun varlığı için düzeltilmiş } \\
\text { olan ampirik sonuçlara göre Kaldor'un ikinci ve } \\
\text { üçüncü yasalarının geçerli olduğu görülmüştür. }\end{array}$ \\
\hline Jeon (2006) & $\begin{array}{l}\text { 1979-2004 } \\
\text { Çin }\end{array}$ & $\begin{array}{c}\text { Zaman seri } \\
\text { analizleri ve } \\
\text { panel veri analizi }\end{array}$ & $\begin{array}{l}\text { Her iki veri setinde de Çin için Kaldor'un } \\
\text { ekonomik büyüme konusundaki hipotezlerinin } \\
\text { geçerli olduğu sonucuna varılmıştır. }\end{array}$ \\
\hline $\begin{array}{l}\text { Karami, } \\
\text { Elahinia ve } \\
\text { Karami (2019), }\end{array}$ & $\begin{array}{l}1995-2016 \\
25 \text { AB Ülkesi }\end{array}$ & Panel veri analizi & $\begin{array}{l}\text { Ekonomik büyümenin imalat sanayi, işgücü ve } \\
\text { teknoloji ile önemli derecede pozitif bir ilişskisi } \\
\text { olduğu ortaya konulmuştur. Ekonomik büyüme ile } \\
\text { yatırımlar arasında bir ilişki bulunamamıştır. }\end{array}$ \\
\hline $\begin{array}{l}\text { Uğurlu ve } \\
\text { Tuncer (2017) }\end{array}$ & $\begin{array}{l}\text { 1995-2011 } \\
\text { Türkiye }\end{array}$ & $\begin{array}{l}\text { Girdi-çıtıtı } \\
\text { analizi }\end{array}$ & $\begin{array}{l}\text { Analizin sonucunda sanayi sektörünün ekonomik } \\
\text { büyüme üzerinde etkisinin olduğu ispatlanmıştır. } \\
\text { Ancak hizmet sektörünün bu etkiye sahip olmadığ } \\
\text { sonucuna varılmıştır. }\end{array}$ \\
\hline $\begin{array}{l}\text { Xie ve } \\
\text { Awokuse } \\
(2014)\end{array}$ & $\begin{array}{l}9 \text { Gelişmekte } \\
\text { Olan Ülke }\end{array}$ & ARDL, GAD & $\begin{array}{l}\text { Tarım sektörünün ekonomik büyümenin bir } \\
\text { dinamiği olduğu ispatlanmıştır. }\end{array}$ \\
\hline Tekkeli (2019) & $\begin{array}{l}\text { 1996-2018 } \\
\text { Türkiye }\end{array}$ & $\begin{array}{c}\text { Johansen } \\
\text { eşbütünleşme, } \\
\text { Granger ve } \\
\text { Toda-Yamamoto } \\
\text { nedensellik testi }\end{array}$ & $\begin{array}{l}\text { Toda-Yamamoto testine göre iki değişken arasında } \\
\text { bir nedensellik bulunmazken, Granger nedensellik } \\
\text { testinde sanayi üretim endeksinden ihracata doğru } \\
\text { bir nedensellik tespit edilmiştir. }\end{array}$ \\
\hline $\begin{array}{c}\text { Behun, } \\
\text { Gavurova, } \\
\text { Tkacova ve } \\
\text { Kotaskova } \\
\text { (2018) }\end{array}$ & $\begin{array}{l}\text { 2000Q1- } \\
\text { 2016Q4 } \\
22 \text { AB Ülkesi }\end{array}$ & $\begin{array}{l}\text { Zaman seri } \\
\text { analizleri }\end{array}$ & $\begin{array}{l}\text { Cross-correlation test ile çoğu ülkede imalat } \\
\text { sanayinde yaşanan değişimler GSYH'yi etkilediği } \\
\text { ifade edilmiştir. }\end{array}$ \\
\hline
\end{tabular}




\begin{tabular}{|c|c|c|}
\hline $\begin{array}{l}\text { Kurt ve Terzi } \\
\quad(2007)\end{array}$ & $\begin{array}{c}\text { 1989-2004 } \\
\text { Türkiye }\end{array}$ & $\begin{array}{l}\text { VAR analizi, etki } \\
\text { tepki analizi ve } \\
\text { varyans } \\
\text { ayrıştırma } \\
\text { yöntemi }\end{array}$ \\
\hline $\begin{array}{c}\text { Khan ve Ahmed } \\
\text { (2012) }\end{array}$ & $\begin{array}{c}\text { 1981-2005 } \\
\text { Pakistan }\end{array}$ & $\begin{array}{c}\text { Zaman serileri } \\
\text { analizi }\end{array}$ \\
\hline $\begin{array}{c}\text { Eze, Nweke ve } \\
\text { Ududechinyere } \\
(2018)\end{array}$ & $\begin{array}{c}1981-2016 \\
\text { Nijerya }\end{array}$ & $\begin{array}{l}\text { ARDL modeli ve } \\
\text { Granger } \\
\text { nedensellik testi }\end{array}$ \\
\hline
\end{tabular}

\begin{tabular}{ccc}
\hline Naudé ve & Gelişmekte & İstatistiki \\
Szirmai (2012) & Olan Ülkeler & değerlendirme
\end{tabular}

Araştırma sonucunda ithalattan verimlilik artışına ve ihracattan ithalat ile ekonomik büyümeye tek yönlü nedenselliğin olduğu sonucuna varılmıştır. Ayrıca, ihracat ve verimlilik artışı, ekonomik büyüme ve verimlilik artışı, ithalat ve ekonomik büyüme arasında çift yönlü bir nedenselliğin olduğu gözlemlenmiştir.

Tarım sektörü ile ekonomik büyüme arasında güçlü bir ilişkinin varlığı tespit edilmiştir.

Değişkenler arasında uzun ve kısa dönemli ilişkinin olduğu tespit edilmiştir. Ayrıca üretim kapasitesi kullanımı, para arzı ve imalat üretiminin reel GSYH'yi olumlu yönde etkilediği sonucuna varılmıştır.

Gelişmekte olan ülkelerin ekonomik göstergeleri geçmiş gelecek ve şimdiki dönemlere ayrılarak değerlendirilmiş ve imalat sanayinin gelişimine engel olan faktörler belirlenerek gelişmekte olan ülkeler için büyümenin tek yolunun imalat sanayi olduğu çıkarımı yapılmıştır.

\begin{tabular}{ccc}
\hline $\begin{array}{c}\text { Öztürk ve } \\
\text { Altınöz (2018) }\end{array}$ & $\begin{array}{c}\text { 1995-2016 } \\
\text { Türkiye }\end{array}$ & $\begin{array}{c}\text { Panel ARDL } \\
\text { modeli }\end{array}$ \\
& & \\
\hline Safdar, & $\begin{array}{c}\text { 1972-2011 } \\
\text { Pakistan }\end{array}$ & ARCH modeli \\
Maqsood ve & & \\
Ullah (2012) & & Gravity modeli \\
Bakari ve & $1982-2016$ & \\
Mabrouki & $\begin{array}{c}\text { Kuzey Afrika } \\
\text { Ülkeleri }\end{array}$ & \\
(2018) & Ulkel &
\end{tabular}

Bağımsız değişkenlerin büyümeye etkisinin pozitif yönlü olduğu tespit edilmiştir. Genel itibari ile firma karlılığının artırılması ekonomik büyümeyi arttırdığ 1 sonucuna ulaşılmıştır.

Test sonuçlarına göre tarım sektöründeki verimliliğin ve istihdamın büyümeyi olumlu yönde etkilediği sonucuna varılmıştır.

Tarımsal ticaretin GSYH ile pozitif bir korelasyona sahip olduğunu göstermiştir. Ancak tarımsal ihracat ile GSYH arasında zayıf bir korelasyon olduğu sonucu elde edilmiştir. Gravity Modeline göre tarım ihracatı ile ekonomik büyüme arasında pozitif ilişki varken, tarım ithalatı ile büyüme arasında ilişkinin bulunmadığı tespit edilmiştir.

\begin{tabular}{ccc}
\hline $\begin{array}{c}\text { Bekun, Ugural } \\
\text { ve Sertoğlu }\end{array}$ & $1981-2013$ & Johansen \\
(2017) & Nijerya & eşbütünleşme ve \\
& & vektör hata \\
& & düzeltme modeli
\end{tabular}

Reel GSYH, tarımsal üretim ve petrol rantlarının uzun vadeli bir denge ilişkisine sahip olduğu ortaya çıkmıştır. VECM sonucuna göre ise tarımsal verimliliğin büyüme üzerinde olumlu bir etkisi olmasına rağmen değişkenlerin uzun vadeli denge yollarına uyum hızlarının düşük olduğu görülmüştür.

\begin{tabular}{|c|c|c|c|}
\hline Attiah (2019) & $\begin{array}{l}\text { 1950-2015 } \\
\text { Afrika ve } \\
\text { Latin } \\
\text { Amerika } \\
\text { Ülkeleri (50 } \\
\text { ülke) }\end{array}$ & $\begin{array}{c}\text { Rassal etkiler } \\
\text { modeli }\end{array}$ & $\begin{array}{l}\text { İmalat sanayi ile ekonomik büyüme arasında bir } \\
\text { ilişkinin olduğu tespit edilirken, hizmet sektörü ile } \\
\text { büyüme arasında bir ilişki bulunmamıştır. }\end{array}$ \\
\hline $\begin{array}{c}\text { Poonyth, } \\
\text { Hassan, Kirsten } \\
\text { ve Calcaterra } \\
\text { (2001) }\end{array}$ & $\begin{array}{c}\text { 1973-1997 } \\
\text { Güney Afrika }\end{array}$ & OLS yöntemi & $\begin{array}{l}\text { Tarımda gerçekleşen \%1'lik bir büyüme diğer } \\
\text { sektörlere göre büyüme üzerinde \%1' den daha } \\
\text { fazla bir etkiye sahip olduğu sonucuna ulaşı1mıştır. }\end{array}$ \\
\hline Herman (2016) & $\begin{array}{l}\text { 1990-2013 } \\
\text { Romanya }\end{array}$ & $\begin{array}{l}\text { İstatistiki } \\
\text { analizler }\end{array}$ & $\begin{array}{l}\text { Romanya sanayisinin, özellikle imalat sektörünün } \\
\text { ülke ekonomisindeki yerini ve istihdam ile } \\
\text { sürdürülebilir kalkınma üzerindeki etkisini } \\
\text { araştırmıştır. } 20 \text { yıldır sanayileşme sürecinde olan } \\
\text { ülkenin işgücü verimliliğinin düşük olması ile orta } \\
\text { ve yüksek teknoloji üretim faaliyetlerinin düşük } \\
\text { seviyede olduğu tespit edilmiştir. }\end{array}$ \\
\hline
\end{tabular}




\section{VERİ ve MODEL}

Çalışmada imalat sanayi ve tarım sektörlerinin ihracatın ithalata (X/M) olan oranı ve ülkelerin makroekonomik büyüklüklerinin bir göstergesi olarak GSYH kullanılmıştır. Çalışmanın zaman dilimi 1998 birinci çeyrek ve 2020 birinci çeyrek dönemini kapsamaktadır. Analize dahil edilen değişkenlerin para birimi TL cinsinden hesaba katılmıştır.

Tablo 2. Değişkenler ve Tanımlayıcı İstatistikler

\begin{tabular}{l|l|c|c|c|c|c}
\hline Değişkenler & Kaynak & Ortalama & Ortanca & Minimum & Maksimum & $\begin{array}{c}\text { Standart } \\
\text { Sapma }\end{array}$ \\
\hline GSYH & $\begin{array}{l}\text { TCBM } \\
\text { (EVDS) }\end{array}$ & $4.24 \mathrm{E}-15$ & 0.020310 & -0.806327 & 0.364583 & 0.268770 \\
\hline $\begin{array}{l}\text { İmalat } \\
\text { Sanayi }\end{array}$ & $\begin{array}{l}\text { TÜIK (ISIC } \\
\text { REV 3 } \\
\text { Düzey 1) }\end{array}$ & $-2.54 \mathrm{E}-17$ & 0.002163 & -0.347415 & 0.373637 & 0.138249 \\
\hline $\begin{array}{l}\text { Tarım ve } \\
\text { Hayvancılık }\end{array}$ & $\begin{array}{l}\text { TÜIK (ISIC } \\
\text { REV 3 } 3 \\
\text { Düzey 2) }\end{array}$ & $-3.12 \mathrm{E}-17$ & -0.071431 & -0.756928 & 0.772255 & 0.330113 \\
\hline
\end{tabular}

Ekonometrik model şu şekildedir:

$$
\text { GSYH }_{t}=\beta_{0}+\beta_{1} \text { imalatsanayi }_{t}+\beta_{2} \text { tarım }_{t}+\varepsilon_{t}
$$

Modelde; imalatsanayi $_{t}$ sektör ihracatının ithalatına oranını gösterirken, tarım $_{t}$ sektör ihracatının ithalata oranını temsil etmektedir.

\section{YÖNTEM ve BULGULAR}

Analizde öncelikle serilerin logaritmik değerleri alınmış ve durağanlık seviyeleri literatürde en fazla kullanılan Augmented Dickey-Fuller (ADF) ve Phillips-Peron (PP) birim kök testleri ile sınanmıştır.

ADF testi, birbirinden farklı model kalıpları ile yapılmaktadır. En genel test istatistiği, deterministik trend ve kesme etkilerinin göz önünde bulundurulmasıly oluşturulan birim kök analizidir. Bu analize göre model şöyledir:

$$
Y_{t}=\mu+\beta \mathrm{t}+\phi_{1} Y_{t-1}+\varepsilon_{t}
$$

Bu modelde kesme ve deterministik trend varsayımı altında birim kök testi yapılır. ADF testi; en net şekilde teorik sonuçları aşağıda verilen regresyonlar dikkate alınarak yapılır:

$$
\begin{array}{cr}
\Delta Y_{t}=\delta Y_{t-1}+\varepsilon_{t} & \text { t-istatistiğ } \\
\Delta Y_{t}=\mu+\delta Y_{t-1}+\varepsilon_{t} & t_{\mu} \text {-istatistiğ } \\
\Delta Y_{t}=\mu+\beta t+\delta Y_{t-1}+\varepsilon_{t} & T_{T} \text {-istatistiği }
\end{array}
$$

Yokluk hipotezi $\delta=0$ ibaresi birim kökün olduğunu göstermektedir. Alternatif hipotez $\delta<0$, serinin durağan yani birim kök içermediğini ifade etmektedir (Sevüktekin ve Çınar, 2017: 330). 
PP testi ise ADF testinin varsayımlarını geliştirerek rassal şokların dağılımını da dikkate alarak yeni bir test geliştirmiştir. Tıpkı ADF testi gibi üç değişik regresyon modeli için uygulamayı genişletiştir (Sevüktekin ve Çınar, 2017: 378). PP testinin matematiksel gösterimi şöyledir:

$$
\begin{gathered}
Y_{t}=\mu+\phi_{1} Y_{t-1} \varepsilon_{t} \\
\left(1-\phi_{1} L\right) Y_{t}=\mu+\varepsilon_{t}
\end{gathered}
$$

Tablo 3. ADF ve PP birim kök testleri

\begin{tabular}{c|c|c|c|c|c|c}
\hline \multicolumn{4}{|c|}{ ADF Testi } & \multicolumn{3}{c}{ PP Testi } \\
\hline Değiş̧kenler & $\begin{array}{c}\text { Sabitli } \\
\text { t-İstatistiği }\end{array}$ & Olasılık & Sonuç & $\begin{array}{c}\text { Sabitli } \\
\text { t-İstatistiği }\end{array}$ & Olasılık & Sonuç \\
\hline İmalat Sanayi & -3.338684 & $0.0160^{* *}$ & $\mathrm{I}(0)$ & -3.472316 & $0.0110^{* *}$ & $\mathrm{I}(0)$ \\
& & & & & & \\
\hline Tarım & -3.377835 & $0.0144^{* *}$ & $\mathrm{I}(0)$ & -3.214313 & $0.0224 * *$ & $\mathrm{I}(0)$ \\
\hline GSYH & -3.313546 & $0.0172^{* *}$ & $\mathrm{I}(0)$ & -3.239619 & $0.0210^{* *}$ & $\mathrm{I}(0)$ \\
\hline
\end{tabular}

Not: *,**,*** sırasıyla $\% 1, \% 5, \% 10$ istatistiki olarak anlamlılı̆̆ ifade etmektedir.

Tablo 3, değişkenlerin durağanlı seviyelerini belirleyen ADF ve PP test sonuçlarını göstermektedir. Logaritmaları alınan değiş̧enler, çeyrek dönemlik verilerle çalışıldığı için mevsimsellik sorunu içerdiği tespit edilmiştir. Mevsimsellik sorunlarından arındırılan değişkenlerin durağanlık seviyelerinin hepsi $\mathrm{I}(0)$ düzeyinde durağan olduğu gözlemlenmiştir. Değişkenlerin durağanlık düzeylerinin benzerlik göstermesi sebebiyle çalışmamızda Johansen eşbütünleşme analizi kullanılmıștır.

Tablo 4. Uygun Gecikme Uzunluğunun Tespit edilmesi

\begin{tabular}{c|c|c|c|c|c|c}
\hline Lag & Logl & LR & FPE & AIC & SC & HQ \\
\hline 0 & 37.28237 & NA & $8.96 \mathrm{e}-05$ & -0.806644 & -0.720433 & -0.771968 \\
\hline 1 & 273.1608 & $449.5565^{*}$ & $4.30 \mathrm{e} 07^{*}$ & $-6.144960^{*}$ & $-5.800115^{*}$ & $-6.006254^{*}$ \\
\hline 2 & 279.9538 & 12.46714 & $4.54 \mathrm{e}-07$ & -6.093030 & -5.489552 & -5.850294 \\
\hline 3 & 287.2832 & 12.93430 & $4.73 \mathrm{e}-07$ & -6.053723 & -5.191611 & -5.706957 \\
\hline 4 & 291.2115 & 6.654941 & $5.35 \mathrm{e}-07$ & -5.934388 & -4.813642 & -5.483593 \\
\hline
\end{tabular}

Johansen eşbütünleşme testi uygulanmadan önce model için en uygun gecikme uzunluğu tespit edilmiştir. Bunun neticesinde incelenen bilgi kriterlerine göre gecikme uzunluğu 1 olarak gözlemlenmiştir.

Eşbütünleşme test sonuçlarının verilmesinde önce modelin stabil ve istikrarlı olduğunu gösteren AR karakteristik polinomunun ters kökleri Şekil 1'de gösterilmiştir. 
Şekil 1. AR Karakteristik Polinomun Ters Kökleri

Inverse Roots of AR Characteristic Polynomial

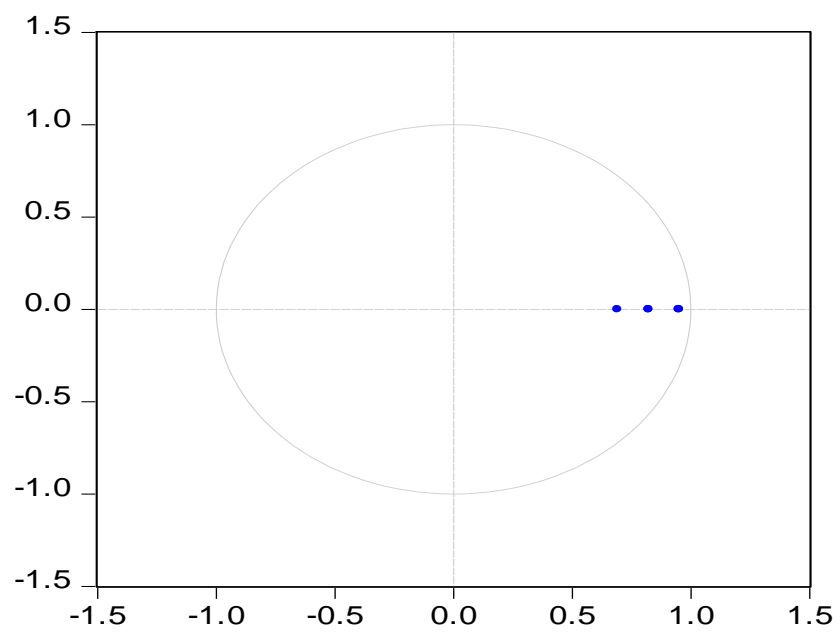

Şekildeki AR karakteristik polinomun ters köklerinin çember sınırlarının içinde kalması, modelin durağanlık ve istikrarsızlık bakımından hiçbir sorun içermediğini ortaya koymaktadır.

Søren Johansen, birden çok değişkenler arasında uzun dönemli bir ilişkinin varlığını tespit etmek için Johansen Eşbütünleşme testini geliştirmiştir. Johansen geliştirmiş olduğu bu analizle, bağımsız Gauss hatalarını içeren otoregresif bir dönem için eşbütünleşme vektörlerinin maksimum olasılık tahmin edicilerini belirlemek ve hipotezlerin belirlenmesi için de bir olasılık oranı testini geliştirmeyi amaçlamıştır. Bu amaç doğrultusunda modele dahil olan değişkenleri içsel kabul ederek analizini geliştirmiştir (Johansen, 1988: 231).

Johansen Eşbütünleşme analizi uygulanmadan önce VAR analizi yardımıyla en uygun gecikme değerleri Akaike ve Schwarz bilgi kriterlerine göre belirlenmiş. Buna göre gecikme aralığ 1 , en uygun model ise sabit terimli ve trendli model olarak tespit edilmiştir.

Tablo 5. Johansen Eşbütünleşme Testi

\begin{tabular}{lcccc}
\hline & \multicolumn{3}{c}{ İz Testi Sonuçları } & \\
\hline Eşbütünleşme Sayısı & Özdeğer & İz istatistiği & $\begin{array}{c}\text { \%5 Kritik } \\
\text { Değer }\end{array}$ & Olasılık \\
\hline Hiç* & 0.325544 & 76.95691 & 42.91525 & $0.0000^{*}$ \\
En Çok 1 & 0.270307 & 42.69205 & 25.87211 & $0.0002^{*}$ \\
En Çok 2 & 0.161031 & 15.27557 & 12.51798 & $0.0169^{* *}$ \\
\hline & & Maksimum Özdeğer Testi & \\
\hline Eşbütünleşme Sayısı & Özdeğer & Maksimum öz istatistiği & \%5 Kritik & Olasılık \\
& & & Değer & \\
\hline Hiç* & 0.32554 & 34.26486 & 25.82321 & $0.0030^{*}$ \\
En Çok 1 & 0.270307 & 27.41647 & 19.38704 & $0.0028^{*}$ \\
En Çok 2 & 0.161031 & 15.27557 & 12.51798 & $0.0169^{* *}$ \\
\hline
\end{tabular}

Not: *, ** işaretler sırasıyla $\% 1$ ve $\% 5$ istatistiki olarak anlamlılığı ifade etmektedir. 
Tablo 5'teki test sonuçlarına göre olasıllk değerlerinin 0,05 'ten küçük değerler alması sonucu $H_{0}$ (Eşbütünleşme yoktur) hipotezi reddedilerek, $H_{1}$ (Eşbütünleşme vardır) hipotezi kabul edilir. Diğer bir söyleyişle uzun dönemde değişkenler arasında birden fazla eşbütünleşme denklemi mevcuttur.

Değişkenler uzun dönemde dengeye gelmesinin belirlenmesi aşamasında değişkenlerin farkları alındığı için değer kayıpları yaşanmaktadır. Bu değer kayıplarının analizde olumsuz etkilerinin ortadan kaldırılması için hata düzeltme modeli uygulanmalıdır.

Modelin yorumlanmasından önce hata düzeltme modeline ait tanımlayıcı değişkenler Tablo 6'da verilmiştir.

Tablo 6. Hata Düzeltme Modelinin Tanımlayıcı İstatistik Sonuçları

\begin{tabular}{lcc}
\hline \multicolumn{1}{c}{ Diagnostik Testler } & Değer & Olasilı \\
\hline Jargue-Bera Normallik & 1,084 & 0,581 \\
\hline Breusch-Pagan-Godfrey & 1.809 & 0.151 \\
\hline ARCH LM & 0.643 & 0.424 \\
\hline Ramsey Reset & 1.765 & 0.177 \\
\hline \multicolumn{1}{c}{ Tablo 6'da }
\end{tabular}

Tablo 6'da yer alan Jargue-Bera Normallik, Breusch-Pagan-Godfrey ve ARCH-LM, Ramsey Reset testleri, oluşturulan hata düzeltme modelinin sırasıyla hata teriminin normal dağıldığını, değişen varyans içermediğini ve model kurma hatasının olmadığını göstermektedir.

Değişkenler arasındaki uzun dönemli ilişkinin bulunmasından sonra bu ilişkinin kısa dönemde dengeden sapma eğilimi vektör hata düzeltme modeli yardımıyla tespit edilir. Hata düzeltme modeli analiz edilirken durağan olan değişkenlerin yanına hata teriminin bir gecikmeli durumu eklenir. Ve bu hata terimi de düzeyde durağan olmak zorundadır.

Tablo 7. Vektör Hata Düzeltme Modeli

\begin{tabular}{l|c|c|c|c}
\hline \multicolumn{1}{c|}{ Değişkenler } & Katsayı & Standart Hata & t-İstatistiği & Olasılık \\
\hline İmalat Sanayi & -0.001455 & 0.050840 & -0.028616 & 0.9772 \\
\hline Tarım & -0.014660 & 0.019648 & -0.746135 & 0.4577 \\
\hline$E C M_{t-1}$ & -0.062207 & 0.016117 & -3.859603 & $0.0002^{*}$ \\
\hline $\mathrm{C}$ & 0.007554 & 0.004254 & 1.775857 & $0.0794 * *$ \\
\hline
\end{tabular}

Not: *, ** işaretleri sırasıyla \%1 ve \%5 istatistiki olarak anlamlılığı ifade etmektedir.

Hata terimi parametresi -1 ile 0 arasında bir değer almalıdır. Eğer bu kısıt sağlanamazsa uygulanan analizde hata düzeltme modelinin uygun olmadığ sonucuna varılır. Analizde elde edilen değer beklentiler yönünde gerçekleşerek -0.06 değerini almıştır. Bu değer, geçen dönem dengedeki bozulmanın bu dönem ne oranda düzeldiğini göstermektedir. Yani geçen dönem dengedeki bir birimlik bozulma bu dönem $\% 0,06$ oranında düzelmektedir. Diğer bir ifadeyle sistemde oluşacak bir bozulma veya dengesizlik $1 / 0,06=16,66$ dönem sonra tekrar dengeye gelecektir. Diğer değişkenler incelendiğinde ise istatistiki bir anlamlılık olmamakla birlikte kısa dönemde imalat sanayi ve tarım sektörü, GSYH'yi sırasıyla \%0,001 ve $\% 0,014$ oranında azaltmaktadır. 
Tablo 8. Granger Nedensellik Testi

\begin{tabular}{lccc}
\hline \multicolumn{1}{c}{$\boldsymbol{H}_{\mathbf{0}}$ Hipotezi } & F-İstatistik & Olasılık & Karar \\
\hline İmalat sanayi GSYH'nin Granger nedeni değildir. & 0.21984 & 0.9529 & $H_{0}$ Kabul \\
GSYH imalat sanayinin Granger nedeni değildir. & 1.30798 & 0.2701 & $H_{0}$ Kabul \\
\hline Tarım GSYH'nin Granger nedeni değildir. & 2.56531 & $0.0341^{*}$ & $H_{0}$ Ret \\
GSYH tarımın Granger nedeni değildir. & 0.47653 & 0.7926 & $H_{0}$ Kabul \\
\hline Tarım imalat sanayinin Granger nedeni değildir. & 2.24893 & $0.0584^{* *}$ & $H_{0}$ Ret \\
İmalat sanayi tarımın Granger nedeni değildir. & 2.12158 & $0.0723^{* *}$ & $H_{0}$ Ret \\
\hline
\end{tabular}

Not: *, ** işaretleri sırasıyla \%5 ve \%10 istatistiki olarak anlamlılığı ifade etmektedir.

Test sonuçlarına göre tarım sektörü GSYH'nin bir Granger nedeniyken; GSYH, tarım sektörünün bir Granger nedeni değildir. Bu bağlamda bu iki değişken arasında tek yönlü bir nedensellik belirlenmiştir. Tarım ve imalat sanayi sektörlerinde ise çift yönlü bir Granger nedensellik tespit edilmiş, ancak imalat sanayi ve GSYH arasında araştırılan dönemler içerisinde bir nedensellik tespit edilememiştir.

\section{SONUÇ}

Ülke ekonomilerinin büyüme performanslarının sağlıklı ve sürdürülebilir şekilde sağlanması ve refah düzeyinin yükseltilebilmesi için ekonomiye etki eden unsurların tespit edilmesi, ekonomi politikalarının da bu bilgiler ışığında tasarlanması gerekmektedir. Bu doğrultuda çalışmada, Türkiye'nin iki önemli sektörü olan imalat sanayi ile tarım sektörlerinin dış ticaret değerlerindeki değişimlerin ülke ekonomisine katkısını belirlemek amaçlanmıştır. 1998 birinci çeyrek ve 2020 birinci çeyrek dönemini kapsayan serilerin, zaman serisi teknikleri ile analiz edilmesi ekonomi politikalarının tasarlanması açısından önem taşımaktadır.

Analizde öncelikle değişkenlerin durağan olup olmadığ 1 ADF ve PP birim kök testleri yardımıyla belirlenmiştir. Değişkenlerin durağanlıkları tespit edildikten sonra, değişkenler arasında uzun ve kısa dönemli eşbütünleşme olup olmadığının belirlenmesini sağlayan Johansen eşbütünleşme testi ile imalat sanayi, tarım sektörü ve büyüme değişkenlerinin birbiri ile bütünleşik olduğu saptanmıştır. Ancak imalat sanayi ve tarım sektörlerinin ithalat değerleri, ihracat değerlerinden büyük olduğu için net dış ticaret gelirleri negatif olarak gerçekleşmiştir.

Dış ticaret değerlerinin negatif olması vektör hata düzeltme modeli katsayılarına da yansıyarak bu iki sektörün ekonomik büyüme üzerinde negatif bir etkiye sahip olduğu gözlemlenmiştir. Değişkenler arasındaki bu etkileşimin yönünü belirlemek için Granger nedensellik testi uygulanmıştır. Granger test sonuçlarında, tarım sektöründen büyümeye tek yönlü, tarım sektörü ve imalat sanayi arasında ise çift yönlü bir Granger nedensellik izlenmiştir.

İmalat sanayi ve ekonomik büyüme arasındaki ilişkiyi araştıran daha önceki çalışmalar göz önünde bulundurulduğunda; Mercan ve Kızılkaya (2014), Naude ve Szirmai (2012), Karami, Elahinia ve Karami (2019), Kurt ve Terzi (2007) imalat sanayinin ekonomik büyüme üzerinde etkili olduğunu göstermektedir. Özellikle Naude ve Szirmai (2012) gelişmekte olan ülkelerin ekonomik büyümeyi sağlamada tek yolunun imalat sanayi olduğunu vurgulamaktadır. Tarım ve ekonomik büyüme arasındaki ilişkiyi belirlemeye çalışan Khan ve Ahmed (2012), 
Bakari ve Mabrouki (2018), Bekun, Ugural, ve Sertoğlu (2017), Poonyth, Hassan, Kirsten ve Calcaterra (2001) ise tarım sektörünün imalat sanayi ile benzer nitelikte olup, ülke ekonomisinin gelişmesinde büyük bir öneme sahip olduğu sonucuna ulaşmışlardır.

Analiz bulgularından hareketle imalat sanayi ile tarım sektörünün GSYH üzerinde azaltıcı bir etki sergilediği söylenebilir. Ancak Granger test sonuçları göz önünde bulundurulduğunda, dış ticaret gelirlerinin pozitif değerler alması ile bu etki olumlu yönde değișecektir. Dolayısıyla buradan hareketle ekonominin bu temel sektörlerinin küresel değer zincirleri aracılığıyla dış ticareti artırmaya yönelik makroekonomik politikalar kapsamında değerlendirilmesinin doğru olacağı ifade edilebilir.

Sonuç olarak bu sektörlerin GSYH lehine bir etki yaratabilmesinin; üretim faktörlerinin verimli kullanılması, teknoloji ve ar-ge yatırımlarının artırılması, nitelikli işgücü sağlanması, gerekli sübvansiyon ve desteklerin yapılması, yerli üretimin özendirilmesi ve ithal edilen malların ikamelerinin ülke içerisinde üretilmesi ve yerli girdi kullanımı adımlarının atılması ile sağlanabileceği ifade edilebilir. Bu mikro düzeydeki politikalar, dış ticarette rekabetçiliği güçlendirecek ve ülke sektörlerinin dış ticaret gelirlerinin artmasını sağlayacaktır. Ana sektörler bazında gerçekleştirilen bu analizin, sektör-spesifik analizler ve sektör bazında politikalarla geliştirilmesi, bu süreçte daha etkin sonuçlar elde edilmesini mümkün hale getirebilir.

\section{KAYNAKÇA}

Attiah, E. (2019). The Role of Manufacturing and Service Sectors in Economic Growth: An Empirical Study of Developing Countries. European Research Studies Journal, XXII(I), 112-127.

Awokuse, T. O., and Xie, R. (2014). Does Agriculture Really Matter for Economic Growth in Developing Countries? Canadian Journal of Agricultural Economics, 1-23, Doi: 10.1111/cjag.12038.

Azra, Khan, D., Ahmed, S. S., and Ahmed, E. (2012). Agriculture and Economic Growth: Empirical Evidence from Pakistan. 2. International Multidisciplinary Conference towards Better Pakistan, (pp. 1-6). Pakistan.

Bakari, S., and Mabrouki, M. (2018). The Impact of Agricultural Trade on Economic Growth in North Africa: . Munich Personal RePEc Archive, 1-14.

Behun, M., Gavurova, B., Tkacova, A., and Kotaskova, A. (2018). The Impact of the Manufacturing Industry on the Economic Cycle of European Union Countries. Journal of Competitiveness, 10(1), 23-39.

Bekun, F. V. (2015). The Contribution of Agricultural Sector on the Economic Growth of Nigeria. Gazimağusa, North Cyprus: Eastern Mediterranean University.

Eze, O. M., Nweke, A. M., and Ududechinyere, C. (2018). An Analysis of the Effect of Manufacturing Sector on the Growth of the Nigerian Economy. Journal of Business and Management, 20(4), 34-46, DOI: 10.9790/487X-2004063446.

Herman, E. (2016). The Importance of the Manufacturing Sector in the Romanian Economy. Elsevier, 976-983, Doi: 10.1016/j.protcy.2016.01.121.

Jeon, Y. (2006). Manufacturing, Increasing Returns and Economic Development in China, 19792004: A Kaldorian Approach . Departman of Economics Working Paper Series, 1-32.

Johansen, S. (1988). Statictical Analysis of Countegration Vectors. Journal of Economic Dynamics and Control , 231-254. 
Karami, M., Elahinia, N., and Karami, S. (2019). The Effect of Manufacturing Value Added on Economic Growth: Empirical Evidence from EUROPA. Journal of Busineus, Economics and Finance, 8(2), 133-146, Doi: 10.17261/Pressacademia.2019.1044.

Kurt, S., ve Terzi, H. (2007). İmalat Sanayi Dış Ticareti Verimlilik ve Ekonomik Büyüme İlişkisi. İktisadi ve İdari Bilimler Dergisi, 21(1), 25-46.

Mercan, M, ve Kızılkaya, O. (2014). Türkiye' de Sanayi Sektörü Ekonomik Büyüme ve Verimlilik İlişkisinin Kaldor Yasaları Çerçevesinde Sınanması: Ekonometrik Bir Analiz. Marmara Üniversitesi İ.I.B. Dergisi, 36(1), 137-160, Doi: 10.14780/iibdergi.201417541.

Naudé, W., and Szirmai, A. (2012). The Importance of Manufacturing in Economic Development: Past, Present and Future Perspectives. Working Paper Series, 1-65.

Novell, J. P., and Marsal, E. V. (1998). Kaldor's Laws and Spatial Dependence: Evidence for the European Regions. Regional Studies, 33(5), 443-451.

Öztürk, S., ve Altınöz, B. (2018). İmalat Sanayi Firma Karlılığının Ekonomik Büyüme Üzerindeki Etkisi: Türkiye için Bir Uygulama. Ömer Halisdemir Üniversitesi İktisadi ve İdari Bilimler Fakültesi Dergisi, 11(3), 18-25, DOI: 10.25287/ohuiibf.433627.

Poonyth, D., Hassan, R., Kirsten, J., and Calcaterra, M. (2001). Is Agricultur Sector Growth a Precondition for Economic Growth? The Case os Sounth Africa. Working Paper, 1-12.

Safdar, i., Maqsood, S., and Ullah, S. (2012). Impact of Agriculture Volatility on Economic Growth: A Case Study of Pakistan. Journel Asian Development Study, 1(2), 24-34.

Sertoğlu, K., Ugural, S., and Bekun, F. V. (2017). The Contribution of Agricultural Sector on Economic Growth of Nigeria. International Journal of Economics and Financial Issues, 7(1), 547-552.

Sevüktekin, M., ve Çınar, M. (2017). Ekonometrik Zaman Serileri Analizi. Bursa: Dora.

Tekkeli, R. (2019). İmalat Sanayinde İhracata Dayalı Büyüme Hipotezinin Geçerliliğinin Test Edilmesi: Türkiye Örneği. Ekonomi, Politika \& Finans Araştırmaları Dergisi, 4(2), 277288, Doi: 10.30784/epfad.579541.

Uğurlu, A. A. ve Tuncer, İ. (2017). Türkiye'de Sanayi ve Hizmet Sektörlerinin Büyüme ve İstihdama Katkıları: Girdi-Çıktı Analizi. Dokuz Eylül Üniversitesi İ̈BF Dergisi, 32(1), 131-165.

\section{SUMMARY}

Countries in the world aim to increase the welfare of society with macroeconomic growth. For this purpose, countries need to identify the factors affecting their economic growth policies and develop economic policies. One of the important dynamics of these policies is foreign trade activities. The globalizing world economy has positive effects on growth as the trade reaches an international dimension. For this, foreign trade revenues of countries should be increased and a sustainable export increase should be ensured.

The main objective of the paper-covered by this literature during 1998Q12020Q1 to determine the effect on the economic growth of the foreign trade of Turkey's manufacturing and agricultural sectors. In the study, GDP was used as a ratio of exports to imports of the manufacturing industry and agriculture sectors and a macroeconomic indicator of countries. With this paper, it has been tried to produce inputs for the decision making processes of policymakers on the basis of the sector, the effects of foreign trade activities of the manufacturing industry, and agriculture sectors, which are the two most basic sectors of the economy, on economic growth.

In the analysis, the logarithmic values of the series were taken, and the stability levels were tested by Augmented Dickey-Fuller (ADF) and Phillips-Peron (PP) unit root tests, which are used most in the literature. According to the 
stationary test results, all the variables stationary at $\mathrm{I}(0)$ level. Since the stationarity levels of the variables are the same, Johansen cointegration analysis was performed. According to the Johansen cointegration test, the manufacturing industry and agriculture sector and growth variables are found to be integrated. However, since the import values of the manufacturing industry and agriculture sectors are larger than their export values, net foreign trade revenues were negative. So, these two sectors have a negative impact on economic growth.

After determining the relationships between the variables, the Granger causality test was used to determine the direction of the relationship. In the Granger test results, a one-way Granger causality was observed in the agricultural sector and a two-way Granger causality between the agricultural sector and the manufacturing industry. Considering the literature investigating the relationship between manufacturing industry and economic growth, it shows that the manufacturing industry has an impact on economic growth. So, this was found to be consistent with the findings.

Based on the analysis findings, it can be said that the manufacturing industry and the agricultural sector have a reducing effect on GDP. However, considering the Granger test results, this effect will change positively as foreign trade revenues take positive values. As a result; sectors can make an impact in favor of GDP by making efficient use of production factors, increasing technology, and $R \& D$ investments, providing qualified workforce, making necessary subsidies and supports, encouraging domestic production and producing substitutes of imported goods within the country and taking domestic input steps. 